Article

\title{
Inverted U-Curve Association between Serum Indoxyl Sulfate Levels and Cardiovascular Events in Patients on Chronic Hemodialysis
}

\author{
Ming-Hsien Tsai ${ }^{1,2} \oplus$, Chung-Hsin Chang ${ }^{1}$, Hung-Hsiang Liou ${ }^{3}$ and Yu-Wei Fang ${ }^{1,2, *}$ \\ 1 Division of Nephrology, Department of Internal Medicine, Shin Kong Wu Ho-Su Memorial Hospital \\ Taipei 11101, Taiwan; chaosmyth.tw@gmail.com (M.-H.T.); chunghsin0303@gmail.com (C.-H.C.) \\ 2 Department of Medicine, Fu-Jen Catholic University School of Medicine, New Taipei City 242062, Taiwan \\ 3 Division of Nephrology, Department of Internal Medicine, Hsin-Jen Hospital, New Taipei City 24243, Taiwan; \\ hh258527@ms23.hinet.net \\ * Correspondence: m005916@gmail.com; Tel.: +886-984160212 or +886-28389491
}

Citation: Tsai, M.-H.; Chang, C.-H.; Liou, H.-H.; Fang, Y.-W. Inverted U-Curve Association between Serum Indoxyl Sulfate Levels and Cardiovascular Events in Patients on Chronic Hemodialysis. J. Clin. Med. 2021, 10, 744. https://doi.org/ 10.3390/jcm10040744

Academic Editor: Magdi Yaqoob

Received: 22 December 2020

Accepted: 10 February 2021

Published: 13 February 2021

Publisher's Note: MDPI stays neutral with regard to jurisdictional claims in published maps and institutional affiliations.

Copyright: (C) 2021 by the authors Licensee MDPI, Basel, Switzerland. This article is an open access article distributed under the terms and conditions of the Creative Commons Attribution (CC BY) license (https:// creativecommons.org/licenses/by/ $4.0 /)$

\begin{abstract}
Background: Protein-bound uremic toxins are associated with cardiovascular disease and mortality in patients with chronic kidney disease. We investigated their association with clinical outcomes in patients undergoing chronic hemodialysis (CHD). Methods: A prospective cohort study was conducted on 86 Taiwanese patients undergoing CHD. The predictors were indoxyl sulfate and p-cresyl sulfate concentrations, with each analyzed as three tertiles. Outcomes were cardiovascular events and all-cause mortality. Results: During a 25-month follow up period, there were 23 cardiovascular events and seven all-cause mortality events. In the crude survival analysis, the second indoxyl sulfate tertile was shown to be a powerful predictor of cardiovascular events compared with the third tertile (hazard ratio (HR), 3.14; 95\% confidence interval (CI), 1.10-8.94), and the first tertile was shown to have a poor but insignificant cardiovascular outcome (HR, 1.09; 95\% CI, 0.30-4.00). Moreover, the predictive power of the second indoxyl sulfate tertile for cardiovascular events remained after adjustment for confounders (HR, 5.42; 95\% CI, 1.67-17.60). Conclusions: An inverse U-curve relationship was observed between the total serum indoxyl sulfate level and cardiovascular events in our CHD patients. A large-scale study is needed to confirm this relationship.
\end{abstract}

Keywords: hemodialysis; indoxyl sulfate; p-cresyl sulfate; protein-bound uremic toxin; cardiovascular disease; mortality

\section{Introduction}

Cardiovascular disease (CVD) is significantly more prevalent in patients on chronic hemodialysis (CHD) than in the general population because of the increased oxidative stress and inflammation, which contribute to vascular abnormalities that are associated with a higher death rate. Therefore, CVD is the main cause of morbidity and mortality among dialysis patients [1-3]. Protein-bound uremic toxins (PBUTs) have been implicated in uremic syndrome and may play an important role in the mortality and morbidity rates of patients with chronic kidney disease (CKD) [4,5]. In dialysis patients, such uremic toxins might have a significant impact on prognosis because of their low clearance rates by dialysis. Of these, indoxyl sulfate (IS) and p-cresyl sulfate (PCS) are perhaps the most widely studied marker molecules [6,7].

IS is derived from the dietary protein "tryptophan", which is metabolized into indole by the intestinal flora, and indole is further converted to IS in the liver. IS plays a key role in CKD deterioration due to its effects on the progression of glomerular sclerosis and renal anemia, as well as the inhibition of endothelial proliferation [8,9]. IS seems to act as an endotheliotoxin leading a principal role on the pathogenesis of CVD in CKD [10]. Moreover, several studies have shown that IS is associated with atherosclerosis, cardiovascular events, 
and skeletal resistance to parathyroid hormone (PTH) in dialysis patients [11,12]. p-Cresol, an end-product of tyrosine metabolism in the gastrointestinal tract, exists predominantly as conjugated PCS in vivo; unconjugated p-cresol is not detectable [13]. It decreases the activation of polymorphonuclear granulocytes in a concentration-dependent manner, inhibits the release of platelet-activating factor by macrophages, and induces hepatotoxicity by increasing aluminum accumulation [14]. In addition, an increased level of serum-free p-cresol was found to be related to higher mortality and morbidity rates [15], as well as vascular access failure [16] in dialysis patients. These findings suggest the importance of PCS and IS in the clinical outcomes of dialysis patients.

However, previous studies have reported neutral findings regarding the relationship between PBUTs and clinical outcomes, including all-cause mortality and CV events in patients with CHD [17,18]. A reverse epidemiology finding linked to protein-energy wasting in dialysis patients has been reported $[19,20]$. Therefore, under the hypothesis that PBUTs might follow a reverse epidemiology pattern in dialysis patients, our study aimed to investigate the association pattern between serum levels of PCS and IS and clinical outcomes (new $\mathrm{CV}$ events and death) in CHD patients during a 25-month follow-up period.

\section{Materials and Methods}

\subsection{Study Design and Population}

This prospective observational cohort study recruited stable hemodialysis patients from June to August 2010 from a single medical center (Figure 1). Initially, 143 participants were screened. Patients with an acute infection, those who had suffered from cardiovascular events in the previous 3 months, those with malignancies or liver disease, those who were participating in drug clinical trials, those with serum albumin $<2.9 \mathrm{~g} / \mathrm{dL}$, those $<18$ years or $>80$ years, and those without agreement were excluded from this study. All participants had been receiving $4 \mathrm{~h}$ of maintenance dialysis three times per week for a minimum of 3 months without reusing the dialyzer. Demographic data were obtained from the participants' medical records upon entry into the study (baseline). Participants were excluded if they left our hemodialysis unit, shifted from hemodialysis to peritoneal dialysis, or received a kidney transplant. Finally, a total of 86 patients with stable CHD were recruited into our study. This study was performed in accordance with the principles of the Declaration of Helsinki and was approved by the Ethics Committee of the Shin-Kong Wu Ho-Su Memorial Hospital (20100608R). Informed consent was obtained from all participants.

\begin{tabular}{|c|c|}
\hline $\begin{array}{c}\text { The recruited } \\
\text { patients }(n=86)\end{array}$ & $\begin{array}{c}\text { The end points are all-cause deaths and } \\
\text { cardiovascular related hospitalization }\end{array}$ \\
\hline
\end{tabular}

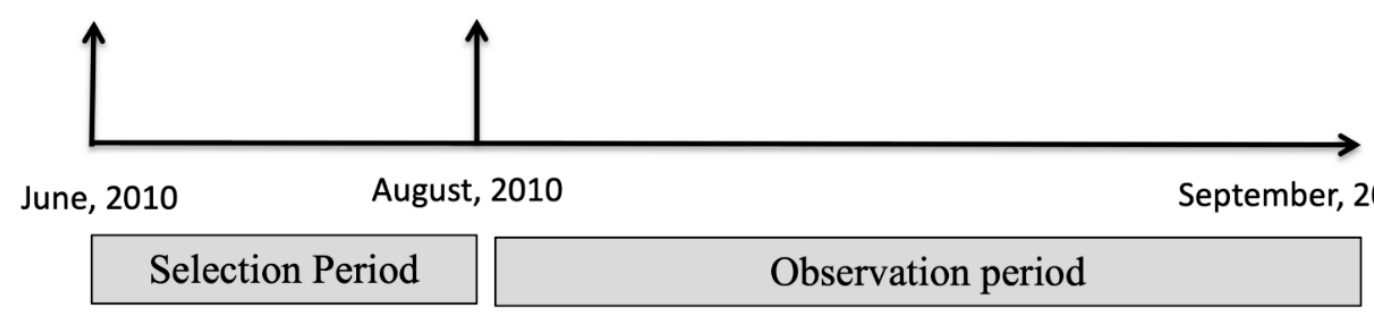

Figure 1. Study design.

\subsection{Laboratory Data}

All blood samples were obtained just before the dialysis procedure after $8 \mathrm{~h}$ of fasting, and the following variables were measured: blood urea nitrogen $(\mathrm{BUN}, \mathrm{mg} / \mathrm{dL})$, creatinine $(\mathrm{Cr}, \mathrm{mg} / \mathrm{dL})$, hemoglobin $(\mathrm{Hb}, \mathrm{g} / \mathrm{dL})$, ionized calcium $(\mathrm{iCa}, \mathrm{mg} / \mathrm{dL})$, phosphate (P, mg/dL), intact PTH (i-PTH, pg/mL), albumin (g/dL), highly sensitive C-reactive protein (hsCRP, $\mathrm{mg} / \mathrm{dL})$, homocysteine $(\mu \mathrm{mol} / \mathrm{L})$, total IS $(\mathrm{mg} / \mathrm{dL})$, total PCS $(\mathrm{mg} / \mathrm{dL})$, total cholesterol (TC, mg/dL), low-density lipoprotein (LDL, mg/dL), high-density lipoprotein (HDL, 
$\mathrm{mg} / \mathrm{dL}$ ), triglycerides (TGs, mg/dL), and dialysis adequacy (Kt/V). Total serum PCS and IS were analyzed using ultra-performance liquid chromatography twice per week (second and third session), and average values were calculated.

\subsection{Event Evaluation}

Participants were followed up until 30 September 2012. During the follow-up period, all-cause deaths and cardiovascular events, including death from cardiac causes, myocardial ischemia, cardiac arrhythmia, cerebrovascular accidents, or new onset of peripheral vascular disease, were recorded. To control the accuracy of the data, the chart notes were reviewed for all admissions. For each participant, the time to event was calculated as the time from the date of entry into the study until the date of the first studied events (mortality and $(\mathrm{V})$, the date of quitting the study, or the end of the study, whichever came first.

\subsection{Statistical Analysis}

We express the data as the mean \pm standard deviation (SD), range (interquartile range $(\mathrm{IQR})$ ) or frequency (percent), as appropriate. For analytical purposes, participants were divided according to IS tertiles and PCS tertiles. Intergroup comparisons were performed using the chi-square test for categorical variables and the Kruskal-Wallis test and MannWhitney U-test for continuous variables when the normal distribution assumption was violated. The Kaplan-Meyer method was used to estimate cardiovascular-event-free rates and overall survival for the IS and PCS tertiles. The log-rank test was used to compare the difference between survival curves. Moreover, univariate and multivariable analyses of cardiovascular events in different IS tertiles were performed using the Cox proportional hazards regression model under the assumption of proportional hazards, which was not violated by testing the interactions between time and variables. A modified stepwise procedure with five modeling steps was used for multivariable analyses. Moreover, a principal components analysis with inspection of the covariance matrix and a rotation method of varimax was performed for dimensionality reduction in parameters to avoid over-adjusting in the multivariable model. Finally, two principal components were generated, which were able to explain $99 \%$ of the variance. A two-sided $p$ value of $<0.05$ was considered statistically significant, and $p \leq 0.018$ was considered statistically significant in the post-hoc comparison, which was performed according to the Bonferroni method. Statistical analyses were conducted using the statistical package for social sciences (SPSS version 26; IBM Inc., Chicago, IL, USA).

\subsection{Patient and Public Involvement}

Patients and the public were not invited to comment on the study design or conduct of the study. However, they will be informed of the study results through publications.

\section{Results}

\subsection{Study Population Characteristics}

Eighty-six stable hemodialysis patients were enrolled in this prospective study. The mean age was $61.8 \pm 12.4$ years, the mean dialysis time was $9.1 \pm 5.4$ years, $61 \%(n=53)$ were males, $42 \%(n=36)$ were diabetic, and $30 \%(n=26)$ had a history of CVD. The distributions of IS (mean, $34.2 \mathrm{mg} / \mathrm{dL} ; \mathrm{SD}, 13.8$ ) and PCS (mean, $25.5 \mathrm{mg} / \mathrm{dL} ; \mathrm{SD}, 18.3$ ) are shown in Figure 2. Table 1 shows the demographic and biochemical characteristics of the 86 included patients in the IS and PCS tertiles. A comparison of patients divided by IS tertiles revealed no significant intergroup differences with respect to age, gender, body mass index (BMI), diabetes mellitus status, systolic and diastolic arterial pressure values, lipid profile, calcium phosphate product, CRP, hemoglobin content, dialysis adequacy, HD vintage, or a positive history for cardiovascular events. However, i-PTH $(p=0.027)$, albumin ( $p=0.012)$, and homocysteine $(p=0.011)$ concentrations differed significantly between IS tertiles. Serum levels of albumin were significantly higher in patients in the third IS tertile than in those in the first and second IS tertiles. Similarly, i-PTH levels were significantly 
higher in the third IS tertile than in the first tertile. Conversely, the homocysteine level was significantly higher for patients in the first IS tertile than in those in the third IS tertile. A comparison of the PCS tertiles revealed no significant intergroup differences with respect to age, gender, BMI, diabetes mellitus status, systolic and diastolic arterial pressures, HD vintage, or a positive history for cardiovascular events. No intergroup differences were noted with respect to biochemical characteristics (Table 1).
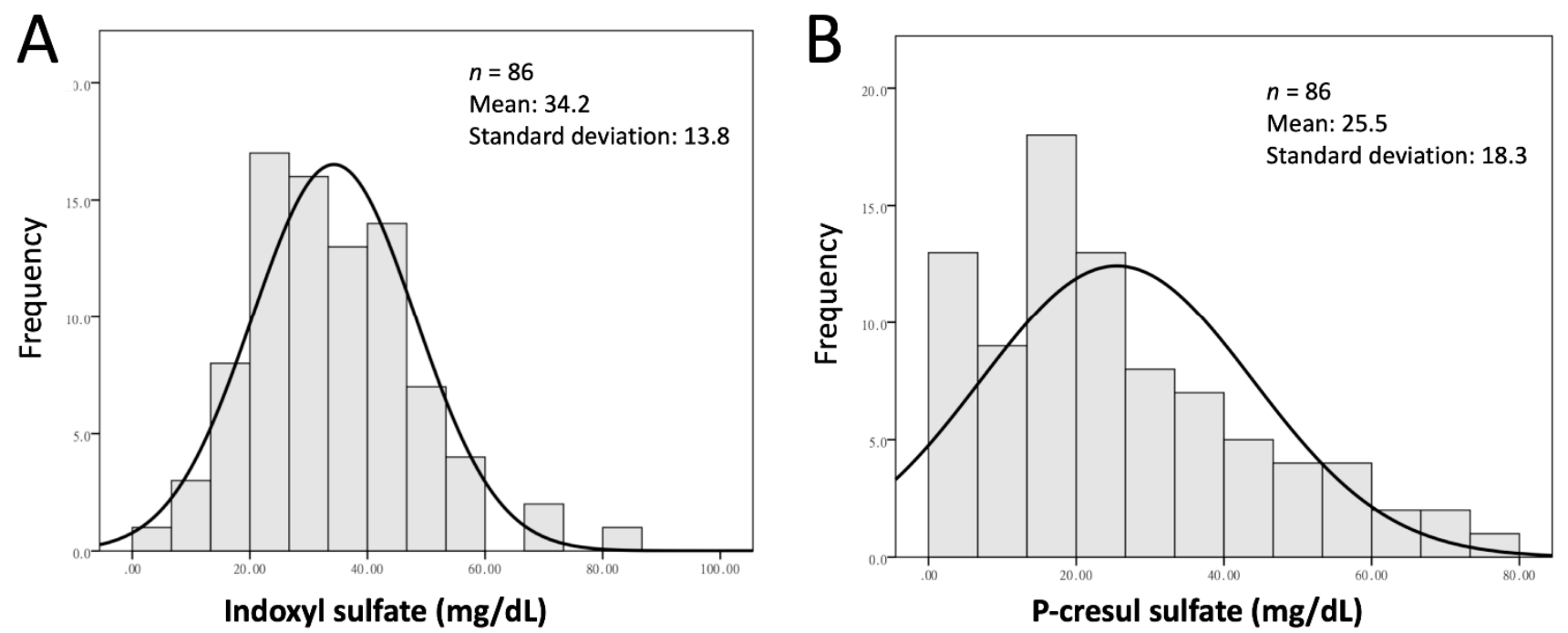

Figure 2. Distribution of serum levels of indoxyl sulfate (A) and P-cresyl sylfate (B).

Table 1. Clinical demographic and biochemical characteristics related to indoxyl sulfate and p-cresyl sulfate concentrations.

\begin{tabular}{|c|c|c|c|c|c|c|c|c|c|}
\hline \multirow[b]{2}{*}{ Parameters } & \multirow{2}{*}{$\begin{array}{c}\text { All } \\
(n=86)\end{array}$} & \multicolumn{4}{|c|}{ Serum IS } & \multicolumn{4}{|c|}{ Serum PCS } \\
\hline & & $\begin{array}{c}\text { 1st Tertile } \\
(n=28)\end{array}$ & $\begin{array}{l}\text { 2nd Tertile } \\
(n=28)\end{array}$ & $\begin{array}{l}\text { 3rd Tertile } \\
\quad(n=30)\end{array}$ & $p$ Value & $\begin{array}{c}\text { 1st Tertile } \\
(n=28)\end{array}$ & $\begin{array}{l}\text { 2nd Tertile } \\
\quad(n=28)\end{array}$ & $\begin{array}{l}\text { 3rd Tertile } \\
\quad(n=30)\end{array}$ & $p$ Value \\
\hline IS (mg/dL) & $34.2 \pm 13.8$ & $5.5-26.2$ & $26.6-39.1$ & $39.5-81$ & - & - & - & - & - \\
\hline PCS (mg/dL) & $25.5 \pm 13.8$ & - & - & - & - & $0.5-15.5$ & $15.7-28$. & $29.1-78.1$ & - \\
\hline Age (year) & $61.8 \pm 12.4$ & $63.0 \pm 10.4$ & $58.9 \pm 14.6$ & $63.3 \pm 11.8$ & 0.330 & $62 \pm 12.3$ & $59.3 \pm 13.0$ & $63.8 \pm 11.8$ & 0.388 \\
\hline Male gender $(n \%)$ & $53(61 \%)$ & $17(60 \%)$ & $16(57 \%)$ & $20(67 \%)$ & 0.752 & $13(46 \%)$ & $20(71 \%)$ & $20(67 \%)$ & 0.123 \\
\hline Vintage (year) & $9.1 \pm 5.4$ & $10.1 \pm 5.8$ & $8.9 \pm 5.4$ & $8.4 \pm 5.0$ & 0.591 & $10.5 \pm 5.6$ & $8.6 \pm 5.0$ & $8.3 \pm 5.5$ & 0.262 \\
\hline $\begin{array}{l}\text { Body mass index } \\
\qquad\left(\mathrm{kg} / \mathrm{m}^{2}\right)\end{array}$ & $22.4 \pm 3.9$ & $22.2 \pm 2.7$ & $22.3 \pm 4.1$ & $23.0 \pm 4.8$ & 0867 & $22.6 \pm 4.0$ & $23.0 \pm 4.2$ & $22.0 \pm 3.8$ & 0.606 \\
\hline Diabetes mellitus ( $n \%)$ & $36(42 \%)$ & $12(43 \%)$ & $10(35 \%)$ & $14(46 \%)$ & 0.694 & $9(32 \%)$ & $12(42 \%)$ & $15(50 \%)$ & 0.384 \\
\hline Presence of CVD ( $n \%)$ & $26(30 \%)$ & $7(25 \%)$ & $10(36 \%)$ & $9(30 \%)$ & 0.683 & $7(25 \%)$ & $10(36 \%)$ & $9(30 \%)$ & 0.683 \\
\hline Systolic BP (mmHg) & $148 \pm 27$ & $150 \pm 26$ & $145 \pm 28$ & $151 \pm 27$ & 0.600 & $146 \pm 25$ & $157 \pm 28$ & $145 \pm 28$ & 0.178 \\
\hline Diastolic BP (mmHg) & $71 \pm 17$ & $71 \pm 17$ & $75 \pm 16$ & $69 \pm 18$ & 0.424 & $71 \pm 11$ & $77 \pm 21$ & $69 \pm 18$ & 0.204 \\
\hline $\begin{array}{l}\text { Ca P product } \\
\left(\mathrm{mg}^{2} / \mathrm{dL}^{2}\right)\end{array}$ & $50.1 \pm 15.5$ & $40.6 \pm 12.4$ & $51.6 \pm 18.3$ & $52.1 \pm 15.2$ & 0.375 & \pm 16.1 & $52.2 \pm 14.0$ & $47.0 \pm 16.2$ & 0.271 \\
\hline iPTH (pg/mL) & $186 \pm 210$ & $154 \pm 250^{a}$ & $172 \pm 179$ & $229 \pm 194$ & 0.027 & $230 \pm 274$ & $182 \pm 190$ & $149 \pm 149$ & 0.349 \\
\hline Albumin (g/dL) & $4.2 \pm 0.4$ & $4.1 \pm 0.4^{\mathrm{a}}$ & $4.1 \pm 0.4^{\mathrm{a}}$ & $4.4 \pm 0.3$ & 0.012 & $4.2 \pm 0.4$ & $4.3 \pm 0.4$ & $4.3 \pm 0.5$ & 0.737 \\
\hline hsCRP (mg/dL) & $1.0 \pm 1.9$ & $0.8 \pm 1.1$ & $1.5 \pm 3.0$ & $0.9 \pm 1.2$ & 0.813 & $1.1 \pm 1.2$ & $0.9 \pm 1.3$ & $1.2 \pm 2.8$ & 0.846 \\
\hline $\begin{array}{l}\text { Homocysteine } \\
(\mu \mathrm{mol} / \mathrm{L})\end{array}$ & $26.6 \pm 12.0$ & $31.3 \pm 17.0^{\mathrm{a}}$ & $26.8=$ & $22.2 \pm 8.0$ & 0.014 & $29.6 \pm 17.3$ & $25.4 \pm 8.4$ & $25.0 \pm 8.4$ & 0.284 \\
\hline Hemoglobin (g/dL) & $10.4 \pm 1.2$ & $10.3 \pm 1.2$ & $10.4 \pm 1.4$ & $10.6 \pm 1.3$ & 0.639 & $10.2 \pm 1.0$ & $10.7 \pm 1.6$ & $10.3 \pm 1.2$ & 0.280 \\
\hline Ferritin (ng/mL) & $566 \pm 311$ & $573 \pm 329$ & $481 \pm 263$ & $639 \pm 328$ & 0.084 & $651 \pm 357$ & $523 \pm 286$ & $525 \pm 280$ & 0.595 \\
\hline Uric acid (mg/dL) & $7.0 \pm 1.3$ & $7.0 \pm 1.3$ & $7.2 \pm 1.5$ & $7.0 \pm 1.2$ & 0.675 & $7.2 \pm 1.5$ & $7.1 \pm 1.1$ & $6.8 \pm 1.3$ & 0.672 \\
\hline $\begin{array}{l}\text { Total cholesterol } \\
(\mathrm{mg} / \mathrm{dL})\end{array}$ & $184 \pm 43$ & $183 \pm 47$ & $174 \pm 46$ & $193 \pm 35$ & 0.119 & $181 \pm 47$ & $187 \pm 45$ & $183 \pm 37$ & 0.833 \\
\hline LDL (mg/dL) & $109 \pm 34$ & $103 \pm 32$ & $105 \pm 36$ & $117 \pm 33$ & 0.275 & $97 \pm 30$ & $117 \pm 37$ & $111 \pm 31$ & 0.078 \\
\hline $\mathrm{HDL}(\mathrm{mg} / \mathrm{dL})$ & $49 \pm 18$ & $45 \pm 14$ & $45 \pm 15$ & $55 \pm 22$ & 0.105 & $50 \pm 16$ & $45 \pm 21$ & $51 \pm 16$ & 0.461 \\
\hline Triglycerides (mg/dL) & $175 \pm 215$ & $229 \pm 329$ & $156 \pm 157$ & $141 \pm 83$ & 0.534 & $227 \pm 356$ & $166 \pm 87$ & $134 \pm 75$ & 0.249 \\
\hline $\mathrm{Kt} / \mathrm{V}$ & $1.38 \pm 0.17$ & $1.37 \pm 0.13$ & $1.40 \pm 0.23$ & $1.38 \pm 0.17$ & 0.970 & $1.40 \pm 1.52$ & $1.33 \pm 1.64$ & $1.40 \pm 0.21$ & 0.274 \\
\hline
\end{tabular}

${ }^{a} p<0.016$, Mann-Whitney $U$-test vs. 3rd tertile. IS, indoxyl sulfate; PCS, p-cresyl sulfate; CVD, cardiovascular disease; BP, blood pressure; iPTH, intact parathyroid hormone; hsCRP; highly sensitive C-reactive protein; LDL, low-density lipoprotein; HDL, high-density lipoprotein; $\mathrm{Kt} / \mathrm{V}$, urea kinetics. 


\subsection{Cardiovascular Events}

Twenty-three patients experienced a new $\mathrm{CV}$ event, with events including coronary artery disease $(n=11)$, peripheral artery occlusive disease $(n=1)$, stroke $(n=2)$, congestive heart failure $(n=1)$, intracranial hemorrhage $(n=2)$, atrial fibrillations $(n=1)$, and cardiovascular death $(n=5)$.

Table 2 shows that being in the second IS tertile (hazard ratio (HR): $3.14,95 \%$ confidence interval (CI): 1.10-8.94, compared with the third tertile), having a history of previous CVD (HR, 2.64; 95\%CI, 1.16-5.99), and having lower albumin (HR, 0.29, 95\% CI, 0.11-0.75), greater hsCRP (HR, 1.26, 95\%CI, 1.11-1.44), and lower LDL (HR, 0.98, 95\%CI, 0.97-1.00) concentrations were associated with a greater likelihood of experiencing cardiovascular events in the crude analysis.

Table 2. Cox proportional regression model for evaluating the relationships among independent variables and clinical outcomes in patients with chronic dialysis.

\begin{tabular}{|c|c|c|c|c|}
\hline \multirow{3}{*}{ Parameters } & \multicolumn{2}{|c|}{ Cardiovascular Event } & \multicolumn{2}{|c|}{ All-Cause Mortality } \\
\hline & \multicolumn{2}{|c|}{ Crude } & \multicolumn{2}{|c|}{ Crude } \\
\hline & HR $(95 \%$ CI) & $p$ & HR $(95 \%$ CI) & $p$ \\
\hline IS (per mg/dL) & $1.00(0.97-1.03)$ & 0.899 & $1.00(0.95-1.06)$ & 0.96 \\
\hline 1st tertile (vs. 3rd tertile) & $1.39(0.42-4.56)$ & 0.585 & $1.63(0.27-9.78)$ & 0.591 \\
\hline 2nd tertile (vs. 3rd tertile) & $3.14(1.10-8.94)$ & 0.031 & $0.53(0.14-7.51)$ & 0.955 \\
\hline PCS (per mg/dL) & $0.99(0.97-1.02)$ & 0.474 & $1.00(0.97-1.04)$ & 0.844 \\
\hline 1st tertile (vs. 3rd tertile) & $1.05(0.34-3.27)$ & 0.972 & $0.68(0.11-4.11)$ & 0.682 \\
\hline 2nd tertile (vs. 3rd tertile) & $2.31(0.85-6.25)$ & 0.099 & $0.67(0.11-4.05)$ & 0.669 \\
\hline Age (per year) & $1.01(0.97-1.04)$ & 0.562 & $1.03(0.96-1.10)$ & 0.319 \\
\hline Male versus female & $0.58(0.26-1.33)$ & 0.205 & $0.77(0.17-3.47)$ & 0.741 \\
\hline Vintage (per year) & $1.02(0.94-1.10)$ & 0.554 & $1.11(0.97-1.27)$ & 0.115 \\
\hline $\mathrm{BMI}\left(\right.$ per $\left.\mathrm{kg} / \mathrm{m}^{2}\right)$ & $0.97(0.87-1.09)$ & 0.689 & $0.94(0.76-1.16)$ & 0.587 \\
\hline Diabetes & $0.68(0.29-1.62)$ & 0.395 & $0.21(0.02-1.78)$ & 0.154 \\
\hline Presence of CVD & $2.64(1.16-5.99)$ & 0.020 & $0.36(0.04-2.99)$ & 0.345 \\
\hline Systolic BP (per mmHg) & $0.99(0.98-1.01)$ & 0.488 & $0.99(0.97-1.02)$ & 0.892 \\
\hline Diastolic BP (per mmHg) & $1.00(0.97-1.02)$ & 0.886 & $0.98(0.94-1.03)$ & 0.611 \\
\hline Ca P product (per $\mathrm{mg}^{2} / \mathrm{dL}^{2}$ ) & $0.99(0.96-1.02)$ & 0.754 & $0.97(0.91-1.03)$ & 0.342 \\
\hline iPTH (per pg/mL) & $0.99(0.99-1.00)$ & 0.473 & $0.99(0.99-1.00)$ & 0.287 \\
\hline Albumin (per g/dL) & $0.29(0.11-0.75)$ & 0.011 & $0.05(0.01-0.28)$ & 0.001 \\
\hline hsCRP (per mg/dL) & $1.26(1.11-1.44)$ & $<0.001$ & $2.15(1.41-3.30)$ & $<0.001$ \\
\hline Homocysteine (per $\mu \mathrm{mol} / \mathrm{L})$ & $0.97(0.93-1.01)$ & 0.253 & $0.98(0.91-1.06)$ & 0.698 \\
\hline Hemoglobin (per g/dL) & $0.92(0.65-1.31)$ & 0.675 & $0.52(0.22-1.22)$ & 0.135 \\
\hline Ln(Ferritin) (per 1 unit) & $1.08(0.69-1.70)$ & 0.732 & $1.18(0.48-2.89)$ & 0.716 \\
\hline Uric acid (per mg/dL) & $0.93(0.68-1.25)$ & 0.616 & $0.51(0.28-0.90)$ & 0.021 \\
\hline $\mathrm{TC}($ per $\mathrm{mg} / \mathrm{dL})$ & $0.99(0.99-1.00)$ & 0.351 & $0.97(0.94-0.99)$ & 0.027 \\
\hline LDL (per mg/dL) & $0.98(0.97-1.00)$ & 0.022 & $0.97(0.95-1.00)$ & 0.060 \\
\hline HDL (per mg/dL) & $1.01(0.99-1.04)$ & 0.116 & $1.01(0.98-1.04)$ & 0.509 \\
\hline Ln(Triglyceride) (per unit) & $0.67(0.36-1.24)$ & 0.198 & $0.40(0.12-1.35)$ & 0.139 \\
\hline $\mathrm{Kt} / \mathrm{V}$ (per unit) & $4.69(0.44-49.7)$ & 0.199 & $4.64(0.07-284)$ & 0.464 \\
\hline
\end{tabular}

Abbreviations: HR, hazard ratio; CI, confidence interval; IS, indoxyl sulfate; PCS, p-cresyl sulfate; BMI, body mass index; CVD, cardiovascular disease; BP, blood pressure; iPTH, intact parathyroid hormone; hsCRP; Ln, natural log transformation; high sensitive C-reactive protein; TC, total cholesterol; LDL, low-density lipoprotein; HDL, high-density lipoprotein; Kt/V, urea kinetics.

The Kaplan-Meyer analysis showed that the serum IS tertile was strongly associated with the rate of cardiovascular events, but PCS was not $\left(\chi^{2}=6.14, p=0.04\right.$ and $\chi^{2}=3.99$, $p=0.13$, respectively) (Figure 3A,B). Table 3 shows the results of cumulative Cox model analyses of the effect of IS on cardiovascular events. Patients in the second IS tertile were found to be at a significantly increased risk of experiencing cardiovascular events. After adjustment for selected predictors of cardiovascular events (model 1: age, gender, and hemodialysis time; model 2: model 1 predictors plus previous CVD and DM; model 3: model 2 predictors plus homocysteine, calcium phosphate product, and hsCRP), patients in the second IS tertile were still found to have a significantly increased risk of experiencing cardiovascular events (models 1-3). In model 4 (model 3 predictors plus LDL and albumin), this association became insignificant. 

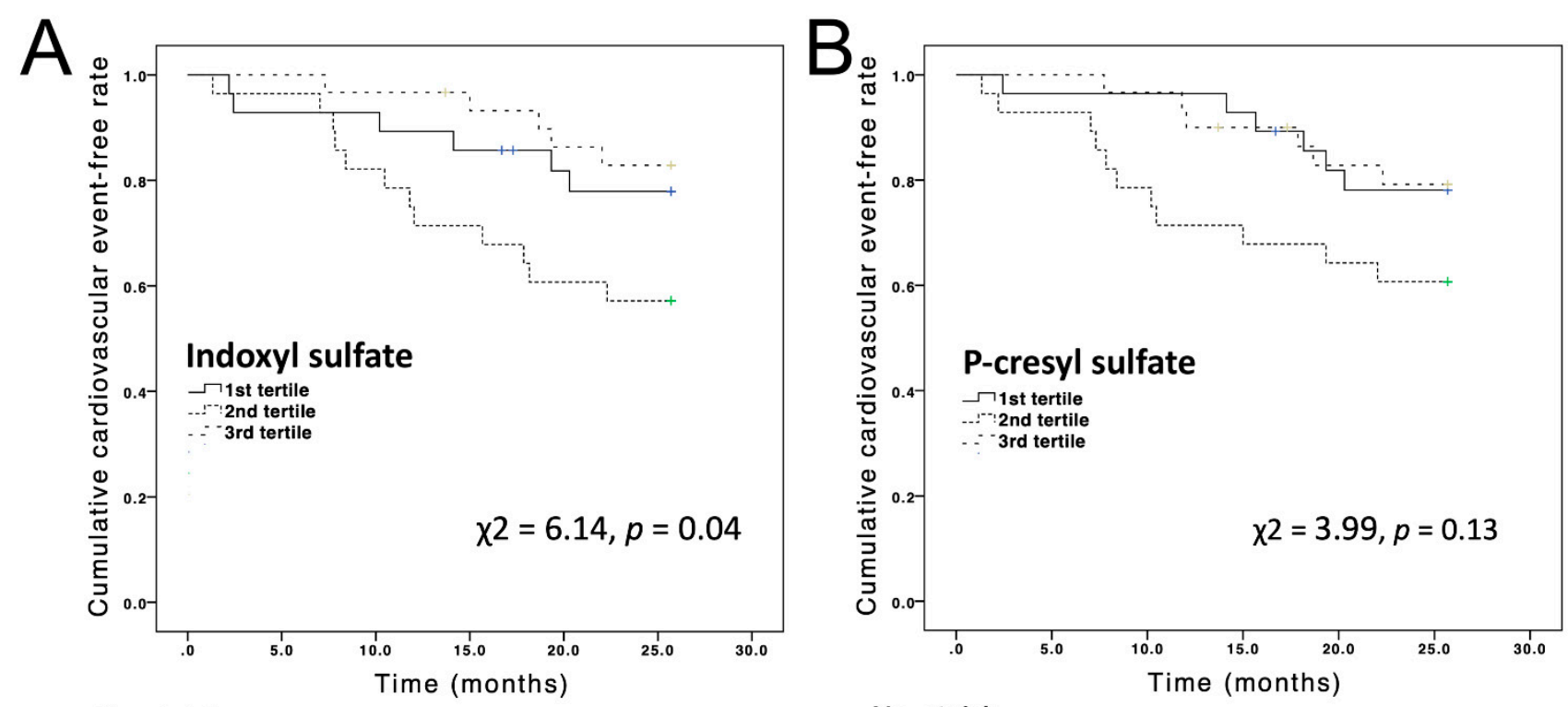

\begin{tabular}{lllllll}
\multicolumn{3}{l}{ No. at risk } & & & & \\
1st & 28 & 26 & 26 & 24 & 21 & 20 \\
2nd & 28 & 27 & 23 & 20 & 17 & 16 \\
3rd & 30 & 30 & 29 & 28 & 25 & 24
\end{tabular}

\begin{tabular}{lllllll}
\multicolumn{3}{l}{ No. at risk } & & & & \\
1st & 28 & 27 & 27 & 26 & 22 & 21 \\
2nd & 28 & 26 & 22 & 20 & 18 & 17 \\
3rd & 30 & 30 & 29 & 26 & 23 & 22
\end{tabular}

Figure 3. Kaplan-Meyer analysis of the associations of serum levels of (A) indoxyl sulfate and (B) P-cresyl sylfate with cardiovascular events.

Table 3. Stepwise multivariate Cox regression analysis of risk factors at baseline for experiencing a cardiovascular event: indoxyl sulfate concentrations shown as tertiles.

\begin{tabular}{|c|c|c|c|}
\hline Models & HR & $95 \% \mathrm{CI}$ & $p$ Value \\
\hline \multicolumn{4}{|l|}{ Unadjusted } \\
\hline 1st tertile & 1.39 & $0.42-4.56$ & 0.58 \\
\hline 2nd tertile & 3.14 & $1.10-8.94$ & 0.03 \\
\hline 3rd tertile & 1 & & \\
\hline \multicolumn{4}{|l|}{ Model 1} \\
\hline 1st tertile & 1.35 & $0.41-4.46$ & 0.61 \\
\hline 2nd tertile & 3.70 & $1.25-10.92$ & 0.01 \\
\hline 3rd tertile & 1 & & \\
\hline \multicolumn{4}{|l|}{ Model 2} \\
\hline 1st tertile & 1.76 & $0.52-5.97$ & 0.36 \\
\hline 2nd tertile & 4.27 & $1.37-13.22$ & 0.01 \\
\hline 3rd tertile & 1 & & \\
\hline \multicolumn{4}{|l|}{ Model 3} \\
\hline 1st tertile & 2.25 & $0.67-8.04$ & 0.214 \\
\hline 2nd tertile & 4.63 & $1.40-15.37$ & 0.012 \\
\hline 3rd tertile & 1 & & \\
\hline \multicolumn{4}{|l|}{ Model 4} \\
\hline 1st tertile & 1.76 & $0.43-7.19$ & 0.430 \\
\hline 2nd tertile & 3.31 & $0.87-12.60$ & 0.079 \\
\hline 3rd tertile & 1 & & \\
\hline \multicolumn{4}{|l|}{ Model 5 * } \\
\hline 1st tertile & 2.19 & $0.63-7.64$ & 0.218 \\
\hline 2nd tertile & 5.42 & $1.67-17.60$ & 0.005 \\
\hline 3rd tertile & 1 & & \\
\hline $\begin{array}{l}\text { Model } 1 \text { is adjusted } \mathrm{f} \\
\text { for diabetes mellitus } \\
\text { for homocysteine, cal } \\
\text { comprises model } 3 \text {, as } \\
\text { and two principal con } \\
\text { of homocysteine, ioniz } \\
\text { lipoprotein, albumin, } \\
\text { hazard ratio; CI, confi }\end{array}$ & $\begin{array}{l}\text { emod } \\
\text { iovas } \\
\text { roduc } \\
\text { ity lip } \\
\text { vo pri } \\
\text { phate, } \\
\text { ritin }\end{array}$ & $\begin{array}{l}\text { el } 2 \text { comprise } \\
\text { lel } 3 \text { compris } \\
\text { tive C-reacti } \\
\text { min concentr } \\
\text { were dimen } \\
\text { in protein, lo } \\
\text { ss index, anc }\end{array}$ & $\begin{array}{l}\text { vell as adjustments } \\
\text { vell as adjustments } \\
\text { entrations. Model } 4 \\
\text { comprises model } 2 \\
\text { rom the parameters } \\
\text { rotein, high-density } \\
\text { Abbreviations: HR, }\end{array}$ \\
\hline
\end{tabular}


In model 5 (model 3 predictors plus two principal components), where over-adjustment was considered, the association became significant. An inverted U-curve association between serum IS tertile and CV events was observed, showing that the second tertile had the worst $\mathrm{CV}$ outcome, followed by the third tertile. The first tertile had the best $\mathrm{CV}$ outcome.

\subsection{All-Cause Mortality Events}

Seven mortality events occurred. These were of cardiovascular $(n=5)$, infectious $(n=1)$, and other $(n=1)$ origin. All-cause mortality was shown to differ significantly with respect to serum albumin (HR, 0.05; 95\% CI, 0.01-0.28), hsCRP (HR, 2.15; 95\% CI, 1.41-3.30), uric acid (HR, 0.51; 95\% CI, 0.28-0.90), and total cholesterol (HR, 0.97; 95\% CI, 0.94-0.99) concentrations in the crude analysis. No significant associations were found among IS, PCS, and all-cause mortality (Table 2). Kaplan-Meyer analysis showed that the serum IS tertile and PCS were not significantly associated with all-cause death $\left(\chi^{2}=0.38, p=0.828\right.$ and $\chi^{2}=0.25, p=0.881$, respectively) (Figure $4 \mathrm{~A}, \mathrm{~B}$ ).

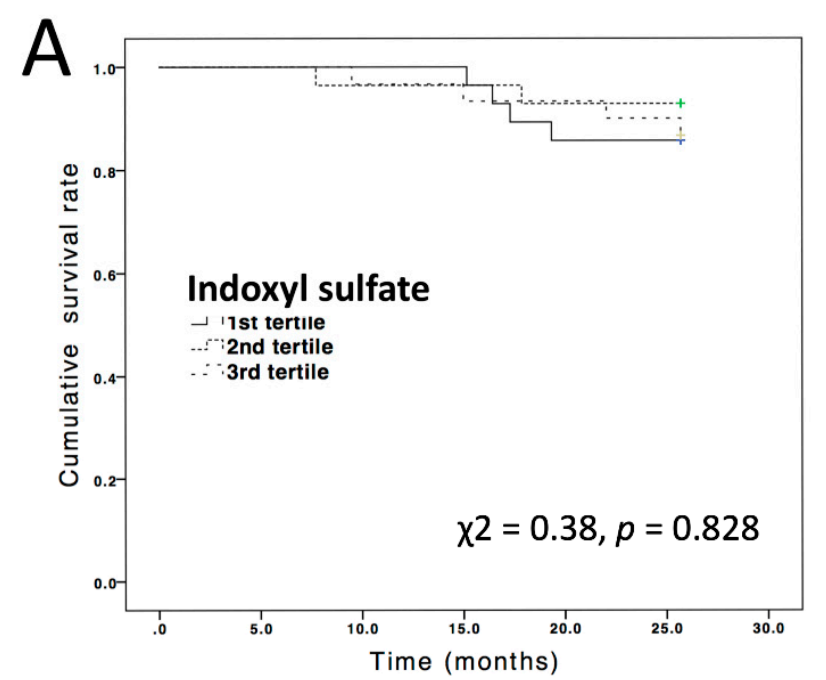

No. at risk

$\begin{array}{lllllll}\text { 1st } & 28 & 28 & 28 & 28 & 24 & 23 \\ \text { 2nd } & 28 & 28 & 27 & 27 & 26 & 26 \\ \text { 3rd } & 30 & 30 & 30 & 29 & 28 & 27\end{array}$

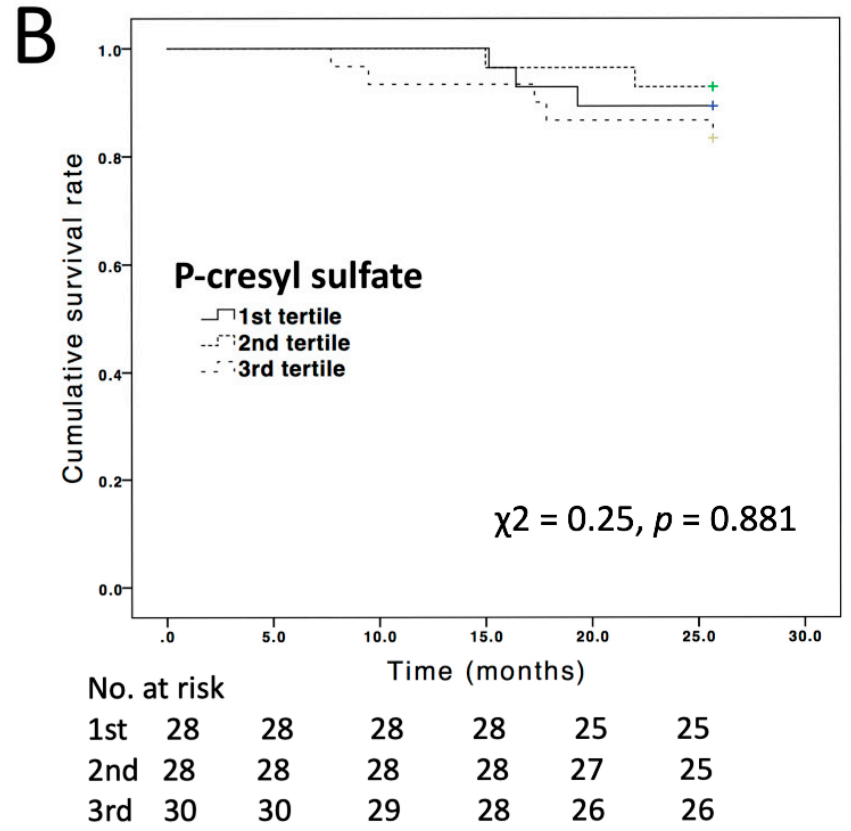

Figure 4. Kaplan-Meyer analysis of associations of serum levels of (A) indoxyl sulfate and (B) P-cresyl sylfate with survival.

\section{Discussion}

To the best of our knowledge, the present study is the first to demonstrate an inverted U-curve relationship between the risk of $\mathrm{CV}$ outcome and serum IS tertile in patients with CHD. Most importantly, we observed that having a moderate serum IS concentration was associated with an increased risk of experiencing a cardiovascular event. Patients with the highest and lowest levels of serum IS within the study cohort had lower levels of risk. After multi-variable adjustment, this association remained. The results of this study could provide physicians with more information about the clinical effects of PBUTs in hemodialysis patients.

Emerging evidence has shown that PBUTs may be directly responsible for the development of CVD in the patients with CKD [21]. Regarding the negative effect of PBUTs on the patients with CHD, some studies have reported serum-free PCS as a cardiovascular risk factor in non-diabetic hemodialysis patients [22], a predictor of infection-related hospitalization in hemodialysis patients [23], and a marker for all-cause mortality and cardiovascular disease in elderly hemodialysis patients [24]. Lin et al. reported that serum IS has no predictive power for CVD but that free $\mathrm{p}$-cresol plays a significant role in CVD development in hemodialysis patients [23]. However, a post-hoc analysis of the HEMO trial, which recruited 1273 participants with a median observation time of 2.3 years, failed 
to demonstrate a linear association between serum levels of PCS and IS and cardiovascular outcomes in dialysis patients [18]. Moreover, a study by van Gelder MK et al. with 80 participants with dialysis who were followed for a median time of 4.3 years showed that the continuous forms of serum IS and PCS had no significant associations with all-cause mortality and CV events [17]. Therefore, the PBUTs seem to have no significantly linear association with $\mathrm{CV}$ events in dialysis patients.

Interestingly, our study shows an inverted U-curve association between serum IS concentration and CV outcome in patients with CHD when the IS concentrations were divided into tertiles. This finding can be explained by the phenomena of reverse epidemiology in dialysis patients due to the effect of nutritional status $[19,20]$. Patients' nutrition might play an important role in this association, as a higher serum IS concentration indicates a better nutritional status, which is a strong predictor for CVD development in hemodialysis patients $[25,26]$. In our study, we observed that a higher serum IS level was significantly associated with a higher serum albumin level and with a lower homocysteine level, which can decrease the development of CVD [27,28]. Moreover, a positive trend between serum IS level and serum lipid level was also noted despite no statistical significance. Such findings in our study supported the positive association between serum IS level and nutrition status in the patients with CHD. Therefore, we hypothesized that the protective effect of better nutrition in hemodialysis patients overcomes the harmful consequences of having a serum IS concentration on the development of CVD. Moreover, this could explain why no significant linear associations between PBUTs and clinical outcomes in the patients with CHD were found in previous studies $[17,18]$.

Notably, the oral charcoal adsorbent AST-120 (KREMEZIN $\left.{ }^{\circledR}\right)$ can adsorb hydrophobic uremic toxins, such as IS and p-cresol, in the gastrointestinal tract and then decrease their levels in the serum $[29,30]$. In clinical studies, administration of AST-120 was reported to prolong the time taken to require dialysis [31] and improve the overall survival outcomes of CKD patients [32]. However, the outcome of long-term AST-120 use in CHD patients is unknown. Better nutrition clearly leads to higher serum IS and PCS levels. Therefore, further studies are needed to elucidate whether AST-120 has an add-on effect on the occurrence of cardiovascular events and the prognosis of dialysis patients with a good nutritional status.

The present study has several limitations. First, we only measured the total IS and PCS levels at the beginning of the study and then observed the occurrence of chosen events. We assumed that the serum levels of IS and PCS would not change over time or would at least increase by the same fraction in all patients. In future studies, a time-dependent Cox regression model [33] with multiple measurements of PCS and IS during the follow-up period will be considered. Second, this study was conducted at a single center, which may limit the generalizability of our findings. Finally, the sample size was small, and the number of outcome events was low; however, this concern may be trivial because a significant association was found between serum IS tertile and the occurrence of CV events. Moreover, we used the principal components analysis method to reduce the dimensionality, which is likely to have avoided over-adjusting in the multivariable analysis.

\section{Conclusions}

Serum IS levels correlated strongly with new onset of a CV event in our CHD patients, but an inverted U-curve association pattern was shown. Interestingly, a reverse epidemiology of IS on CVD was observed in CHD patients. However, further clinical studies are still required to confirm our findings.

Supplementary Materials: The following are available online at https:/ / www.mdpi.com/2077-038 3/10/4/744/s1, Supplementary data S1: The data presented in this study.

Author Contributions: Conceptualization, C.-H.C. and Y.-W.F.; data curation, M.-H.T. and Y.-W.F.; formal analysis, M.-H.T. and H.-H.L.; investigation, M.-H.T., C.-H.C. and Y.-W.F.; methodology, M.-H.T.; project administration, M.-H.T., C.-H.C. and Y.-W.F.; resources, M.-H.T., C.-H.C., H.-H.L. and 
Y.-W.F.; supervision, M.-H.T. and Y.-W.F.; validation, M.-H.T. and Y.-W.F.; visualization, M.-H.T. and Y.-W.F.; writing—original draft, M.-H.T. and C.-H.C.; writing—review and editing, M.-H.T., C.-H.C., H.-H.L. and Y.-W.F. All authors have read and agreed to the published version of the manuscript.

Funding: The Shin Kong Wu Ho-Su Memorial Hospital (SKH-8302-106-DR-04) sponsored this study.

Institutional Review Board Statement: This study was performed in accordance with the principles of the Declaration of Helsinki and was approved by the Ethics Committee of the Shin-Kong Wu Ho-Su Memorial Hospital (20100608R).

Informed Consent Statement: Informed consent was obtained from all participants.

Data Availability Statement: The data presented in this study are available in supplementary data S1.

Acknowledgments: We would like to thank the hemodialysis patients in Shin Kong Wu Ho-Su Memorial Hospital who provided their samples to our study.

Conflicts of Interest: The authors have no conflict of interest to disclose.

\section{References}

1. Tsai, M.H.; Liou, H.H.; Leu, J.G.; Yen, M.F.; Chen, H.H. Sites of peripheral artery occlusive disease as a predictor for all-cause and cardiovascular mortality in chronic hemodialysis. PLOS ONE 2015, 10, e0128968. [CrossRef]

2. Chen, S.C.; Huang, J.C.; Su, H.M.; Chiu, Y.W.; Chang, J.M.; Hwang, S.J.; Chen, H.C. Prognostic cardiovascular markers in chronic kidney disease. Kidney Blood Press Res. 2018, 43, 1388-1407. [CrossRef]

3. Ravarotto, V.; Simioni, F.; Pagnin, E.; Davis, P.A.; Calo, L.A. Oxidative stress-chronic kidney disease-cardiovascular disease: A vicious circle. Life Sci. 2018, 210, 125-131. [CrossRef]

4. Liu, W.C.; Tomino, Y.; Lu, K.C. Impacts of indoxyl sulfate and p-cresol sulfate on chronic kidney disease and mitigating effects of ast-120. Toxins 2018, 10, 367. [CrossRef]

5. Barreto, F.C.; Barreto, D.V.; Liabeuf, S.; Meert, N.; Glorieux, G.; Temmar, M.; Choukroun, G.; Vanholder, R.; Massy, Z.A.; European Uremic Toxin Work Group. Serum indoxyl sulfate is associated with vascular disease and mortality in chronic kidney disease patients. Clin. J. Am. Soc. Nephrol. 2009, 4, 1551-1558. [CrossRef] [PubMed]

6. Clark, W.R.; Dehghani, N.L.; Narsimhan, V.; Ronco, C. Uremic toxins and their relation to dialysis efficacy. Blood Purif. 2019, 48, 299-314. [CrossRef]

7. Deltombe, O.; Van Biesen, W.; Glorieux, G.; Massy, Z.; Dhondt, A.; Eloot, S. Exploring protein binding of uremic toxins in patients with different stages of chronic kidney disease and during hemodialysis. Toxins 2015, 7, 3933-3946. [CrossRef]

8. Leong, S.C.; Sirich, T.L. Indoxyl sulfate-review of toxicity and therapeutic strategies. Toxins 2016, 8, 358. [CrossRef]

9. Dias, G.F.; Bonan, N.B.; Steiner, T.M.; Tozoni, S.S.; Rodrigues, S.; Nakao, L.S.; Kuntsevich, V.; Pecoits Filho, R.; Kotanko, P.; Moreno-Amaral, A.N. Indoxyl sulfate, a uremic toxin, stimulates reactive oxygen species production and erythrocyte cell death supposedly by an organic anion transporter 2 (oat2) and nadph oxidase activity-dependent pathways. Toxins 2018, 10, 280. [CrossRef]

10. Lano, G.; Burtey, S.; Sallee, M. Indoxyl sulfate, a uremic endotheliotoxin. Toxins 2020, 12, 229. [CrossRef]

11. Guo, C.C.; Xia, W.W.; Zhang, A.H. [research progress of the uremic toxin indoxyl sulfate in cardiovascular complication of end-stage renal diseases]. Sheng Li Xue Bao 2018, 70, 657-662. [PubMed]

12. He, X.; Jiang, H.; Gao, F.; Liang, S.; Wei, M.; Chen, L. Indoxyl sulfate-induced calcification of vascular smooth muscle cells via the pi3k/akt/nf-kappab signaling pathway. Microsc. Res. Tech. 2019, 82, 2000-2006. [CrossRef] [PubMed]

13. Sitkin, S.I.; Tkachenko, E.I.; Vakhitov, T.Y. Metabolic dysbiosis of the gut microbiota and its biomarkers. Eksp. Klin. Gastroenterol. 2016, 12, 6-29. [PubMed]

14. Chao, C.T.; Chiang, C.K. Uremic toxins, oxidative stress, and renal fibrosis: An interwined complex. J. Ren. Nutr. 2015, 25, 155-159. [CrossRef] [PubMed]

15. Bammens, B.; Evenepoel, P.; Keuleers, H.; Verbeke, K.; Vanrenterghem, Y. Free serum concentrations of the protein-bound retention solute p-cresol predict mortality in hemodialysis patients. Kidney Int. 2006, 69, 1081-1087. [CrossRef] [PubMed]

16. Chen, T.C.; Wang, C.Y.; Hsu, C.Y.; Wu, C.H.; Kuo, C.C.; Wang, K.C.; Yang, C.C.; Wu, M.T.; Chuang, F.R.; Lee, C.T. Free p-cresol sulfate is associated with survival and function of vascular access in chronic hemodialysis patients. Kidney Blood Press Res. 2012, 35, 583-588. [CrossRef]

17. van Gelder, M.K.; Middel, I.R.; Vernooij, R.W.M.; Bots, M.L.; Verhaar, M.C.; Masereeuw, R.; Grooteman, M.P.; Nube, M.J.; van den Dorpel, M.A.; Blankestijn, P.J.; et al. Protein-bound uremic toxins in hemodialysis patients relate to residual kidney function, are not influenced by convective transport, and do not relate to outcome. Toxins 2020, 12, 234. [CrossRef]

18. Shafi, T.; Sirich, T.L.; Meyer, T.W.; Hostetter, T.H.; Plummer, N.S.; Hwang, S.; Melamed, M.L.; Banerjee, T.; Coresh, J.; Powe, N.R. Results of the hemo study suggest that p-cresol sulfate and indoxyl sulfate are not associated with cardiovascular outcomes. Kidney Int. 2017, 92, 1484-1492. [CrossRef] 
19. Hanna, R.M.; Ghobry, L.; Wassef, O.; Rhee, C.M.; Kalantar-Zadeh, K. A practical approach to nutrition, protein-energy wasting, sarcopenia, and cachexia in patients with chronic kidney disease. Blood Purif. 2020, 49, 202-211. [CrossRef]

20. Zha, Y.; Qian, Q. Protein nutrition and malnutrition in ckd and esrd. Nutrients 2017, 9, 208. [CrossRef]

21. Hung, S.C.; Kuo, K.L.; Wu, C.C.; Tarng, D.C. Indoxyl sulfate: A novel cardiovascular risk factor in chronic kidney disease. J. Am. Heart Assoc. 2017, 6, e005022. [CrossRef]

22. Meijers, B.K.; Bammens, B.; De Moor, B.; Verbeke, K.; Vanrenterghem, Y.; Evenepoel, P. Free p-cresol is associated with cardiovascular disease in hemodialysis patients. Kidney Int. 2008, 73, 1174-1180. [CrossRef]

23. Lin, C.J.; Wu, C.J.; Pan, C.F.; Chen, Y.C.; Sun, F.J.; Chen, H.H. Serum protein-bound uraemic toxins and clinical outcomes in haemodialysis patients. Nephrol. Dial. Transpl. 2010, 25, 3693-3700. [CrossRef] [PubMed]

24. Wu, I.W.; Hsu, K.H.; Hsu, H.J.; Lee, C.C.; Sun, C.Y.; Tsai, C.J.; Wu, M.S. Serum free p-cresyl sulfate levels predict cardiovascular and all-cause mortality in elderly hemodialysis patients-A prospective cohort study. Nephrol. Dial. Transpl. 2012, 27, 1169-1175. [CrossRef] [PubMed]

25. Marcelli, D.; Usvyat, L.A.; Kotanko, P.; Bayh, I.; Canaud, B.; Etter, M.; Gatti, E.; Grassmann, A.; Wang, Y.; Marelli, C.; et al. Body composition and survival in dialysis patients: Results from an international cohort study. Clin. J. Am. Soc. Nephrol. 2015, 10, 1192-1200. [CrossRef]

26. Xiong, J.; Wang, M.; Zhang, Y.; Nie, L.; He, T.; Wang, Y.; Huang, Y.; Feng, B.; Zhang, J.; Zhao, J. Association of geriatric nutritional risk index with mortality in hemodialysis patients: A meta-analysis of cohort studies. Kidney Blood Press Res. 2018, 43, 1878-1889. [CrossRef] [PubMed]

27. Karger, A.B.; Steffen, B.T.; Nomura, S.O.; Guan, W.; Garg, P.K.; Szklo, M.; Budoff, M.J.; Tsai, M.Y. Association between homocysteine and vascular calcification incidence, prevalence, and progression in the mesa cohort. J. Am. Heart Assoc. 2020, 9, e013934. [CrossRef] [PubMed]

28. Chien, S.C.; Chen, C.Y.; Lin, C.F.; Yeh, H.I. Critical appraisal of the role of serum albumin in cardiovascular disease. Biomark Res. 2017, 5, 31. [CrossRef]

29. Asai, M.; Kumakura, S.; Kikuchi, M. Review of the efficacy of ast-120 (kremezin((r))) on renal function in chronic kidney disease patients. Ren. Fail 2019, 41, 47-56. [CrossRef]

30. Lee, C.T.; Hsu, C.Y.; Tain, Y.L.; Ng, H.Y.; Cheng, B.C.; Yang, C.C.; Wu, C.H.; Chiou, T.T.; Lee, Y.T.; Liao, S.C. Effects of ast-120 on blood concentrations of protein-bound uremic toxins and biomarkers of cardiovascular risk in chronic dialysis patients. Blood Purif. 2014, 37, 76-83. [CrossRef]

31. Ueda, H.; Shibahara, N.; Takagi, S.; Inoue, T.; Katsuoka, Y. Ast-120, an oral adsorbent, delays the initiation of dialysis in patients with chronic kidney diseases. Ther. Apher. Dial. 2007, 11, 189-195. [CrossRef] [PubMed]

32. Ueda, H.; Shibahara, N.; Takagi, S.; Inoue, T.; Katsuoka, Y. Ast-120 treatment in pre-dialysis period affects the prognosis in patients on hemodialysis. Ren. Fail. 2008, 30, 856-860. [CrossRef] [PubMed]

33. Fisher, L.D.; Lin, D.Y. Time-dependent covariates in the cox proportional-hazards regression model. Annu. Rev. Public Health 1999, 20, 145-157. [CrossRef] [PubMed] 